\title{
Incidental Finding of Raised Random Blood Sugar in Cases Presenting with Erectile Dysfunction \\ Farhan Qureshi, ${ }^{1}$ Imran Hussain, ${ }^{1}$ Shayan Rahim Kanjoo ${ }^{1}$
}

\begin{abstract}
Background: Background: Erectile dysfunction is quite widely present in our populations, as men wish to maintain sexual desire and function despite aging.

Objective: To determine the frequency of raised random blood sugar in cases presenting with erectile dysfunction.

Methodology: Study design; Cross sectional study. Place of study; Department of Urology, Sheikh Zayed Hospital, Rahim Yar Khan. Duration; January to December 2018. In this study, all the consecutive male cases, with age 20 years or more, presenting with erectile dysfunction of at least one month or more, were included. Raised BSR was labelled when there was a level of random blood sugar was more than $140 \mathrm{mg} / \mathrm{dl}$.

Results: In the present study, there were 100 males with erectile dysfunction, with mean age of $48.67 \pm 5.13$ year. Raised BSR was seen in 24 (24\%) out of 100 cases. There was no significant difference in terms of age, and BMI in both groups, with p values of 0.87 and 0.91 respectively. Raised BSR was significantly high in cases that had duration of erectile dysfunction more than 3 months where it was seen in $21(31.34 \%)$ of cases as compared to $3(9.09 \%)$ of cases with duration less than this with $\mathrm{p}$ value of 0.01 .

Conclusion: Raised random blood sugar is common in cases with erectile dysfunction and seen in every one out of four cases and is significantly high in cases with duration of erectile function more than 3 months.
\end{abstract}

Key words: Blood Sugar, Erectile Dysfunction, BMI

\section{Introduction}

Erectile dysfunction (ED) is one of the commonly encountered entity at the Urology clinics and is a point of great concern in all age subjects, due to retention of sexual desire despite aging. ${ }^{1}$ Its prevalence is highly variable due to difference in the data collection subsets and prevalence of certain diseases across the globe and is found in 20 to $85 \%$ of the cases. ${ }^{1,2}$

There are number of underlying etiologies that can lead to this and include all aspects of structural, functions, physiological and psychological factors that result in erectile dysfunction and hence need to be addressed, work out and managed accordingly as it can impact the great burden on one's social, psychological and marital life ${ }^{3}$ Diabetes Mellitus (DM) is one of the biggest concerns in the modern community as its number is on the rise in the developing countries also due to change in the life style, decreased physical activities and more of junk foods. It is a highly morbid condition and can affect the body largely through its micro and macro vascular complications. $^{4,5}$
There is a direct association between erectile dysfunction and DM. The basic underlying pathophysiology comprises a spectrum of abnormalities in neurological, vasogenic and psychological aspects. There is significant impairment in the mechanism of production and attribution of endothelial related nitric oxide in cases suffering from Diabetes Mellitus, which is the major neuronal factor for mediation of corporal smooth muscles relaxation and erection; hence leading to erectile dysfunction. ${ }^{6}$ However, there are certain other complications as well, that are indirectly associated with DM as well as ED and these include, Hypertension, obesity, metabolic syndrome, atherosclerosis, autonomic dysfunction, dyslipidaemias etc. it has shown a great negative impact on quality of life in such cases. ${ }^{6}$

The risk of ED is highest in cases with DM as compared to all other physiological and psychological factors and data has reported that the ED starts at relatively earlier ages in cases with DM as compared to the same age of the controls. Few of the studies have shown that the degree of uncontrolled DM has also been associated with

1. Department of Urology, Sheikh Zayed Medical College/Hospital, Rahim Yar Khan, University of Health Sciences Lahore, Pakistan

Correspondence: Dr. Farhan Qureshi, Assistant Professor, Department of Urology, Sheikh Zayed Medical College/Hospital, Rahim Yar Khan, Pakistan. 
DM. ${ }^{8,9}$ This study was planned to assess the frequency of the raised random blood sugar in cases with erectile dysfunction, to quantify this burden that how often erectile dysfunction presents as one cardinal manifestation of Diabetes Mellitus.

\section{Methodology}

This cross sectional study was carried out Department of Urology, Sheikh Zayed Hospital, Rahim Yar Khan, between January to December 2018. In this study, all the consecutive male cases, with age 20 years or more presenting with erectile dysfunction of at least one month or more, were included. The cases with already known history of DM, having end stage liver or renal failure or documented cases of any psychological disorder were excluded from this study. Then these cases underwent serum glucose level by simple electronic glucometer.

Raised Random Blood Sugar was labelled as "yes" where the level of this was more than 140 $\mathrm{mg} / \mathrm{dl}$. The variables included were; random blood sugar, age in years, duration of erectile dysfunction in months and BMI. The data was analyzed on SPSS version 23.0. Effect modifiers were controlled and post stratification chi square test was applied taking $\mathrm{p} \leq 0.05$ as significant. Ethical approval was sought from Institutional Review Board before starting this study and also we ensured informed verbal consent from each study subject for inclusion in study.

\section{Results}

In the present study, there were a total of 100 males having erectile dysfunction, with mean age of $48.67 \pm 5.13$ year and mean duration of erectile dysfunction at presentation was $3.47 \pm 0.71$ months as shown in table I.

Raised BSR was seen in $24(24 \%)$ out of 100 cases. (Figure I) There was no significant difference in terms of age, and BMI in both groups with $p$ values of 0.87 and 0.91 respectively as shown in tables II. However, raised BSR was significantly high in cases that had duration of ED more than 3 months where it was seen in 21 $(31.34 \%)$ of cases as compared to $3(9.09 \%)$ of cases with duration less than this, with $p$ value of 0.01 as shown in table II.
Table I: Demographics and clinical variables. $(n=100)$

\begin{tabular}{|c|c|c|}
\hline Variables & Mean \pm SD & Range \\
\hline Age (years) & $48.67 \pm 5.13$ & $31-67$ \\
\hline $\begin{array}{c}\text { Duration of ED } \\
\text { (months) }\end{array}$ & $3.47 \pm 0.71$ & $1-12$ \\
\hline BMI (kg/m $\mathbf{m}^{\mathbf{2}}$ & $28.37 \pm 3.11$ & $25-36$ \\
\hline
\end{tabular}

Figure I: Raised Random Blood Sugar in Erectile Dysfunction.

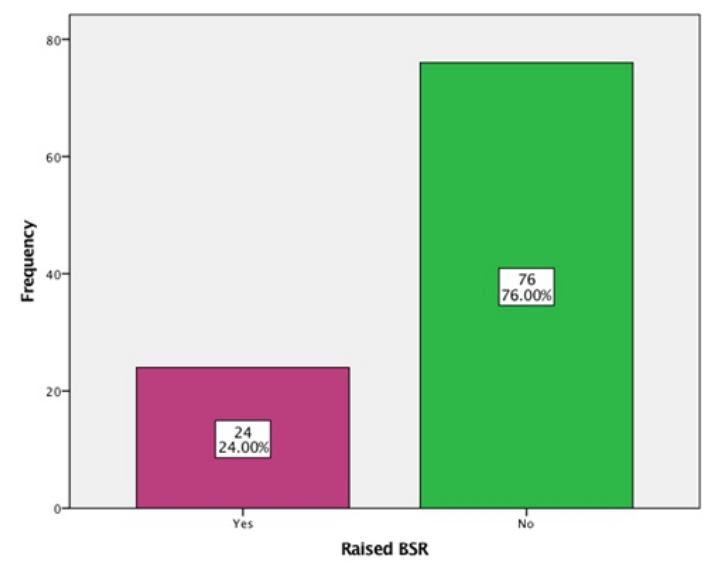

Table II: Raised BSR and age, BMI and Duration in cases with Erectile Dysfunction. $(n=100)$

\begin{tabular}{|c|c|c|c|c|}
\hline Variable & \multicolumn{3}{|c|}{ Raised BSR } & \multirow{2}{*}{$P$ value } \\
\hline Age & Yes & No & Total & \\
\hline $\begin{array}{c}\text { Up to } 50 \\
\text { years }\end{array}$ & $6(23.07 \%)$ & $20(76.93 \%)$ & $26(100 \%)$ & \multirow{3}{*}{0.87} \\
\hline$>50$ & $18(24.32 \%)$ & $56(75.68 \%)$ & $74(100 \%)$ & \\
\hline Total & $24(24 \%)$ & $76(76 \%)$ & $100(100 \%)$ & \\
\hline \multirow{2}{*}{ BMI } & \multicolumn{3}{|c|}{ Raised BSR } & \multirow{2}{*}{$P$ value } \\
\hline & Yes & No & Total & \\
\hline Up to 30 & $14(24.13 \%)$ & $44(75.87 \%)$ & $58(100 \%)$ & \multirow{3}{*}{0.91} \\
\hline$>30$ & $10(23.80 \%)$ & $32(76.20 \%)$ & $42(100 \%)$ & \\
\hline Total & $24(24 \%)$ & $76(76 \%)$ & $100(100 \%)$ & \\
\hline Duration & \multicolumn{3}{|c|}{ Raised BSR } & \multirow{2}{*}{ P value } \\
\hline of ED & Yes & No & Total & \\
\hline $\begin{array}{l}\text { Up to } 3 \\
\text { months }\end{array}$ & $3(9.09 \%)$ & $30(90.91 \%)$ & $33(100 \%)$ & \multirow{3}{*}{0.01} \\
\hline $\begin{array}{c}>3 \\
\text { months }\end{array}$ & $21(31.34 \%)$ & $46(68.66 \%)$ & $67(100 \%)$ & \\
\hline Total & $24(24 \%)$ & $76(76 \%)$ & $100(100 \%)$ & \\
\hline
\end{tabular}

\section{Discussion}

Diabetes Mellitus has a direct association with erectile dysfunctions, due to dysregulated glucose metabolism and associated micro and macro vascular changes in the body and neuropathies. Type II DM is always a delayed diagnosis as its symptoms 
are vague and there is always a lag period of significant time until it is diagnosed. Erectile dysfunction can be one leading symptoms to work up for underlying causes and raised blood sugar levels may indicate an overt underling DM, but the data regarding this was lacking. ${ }^{10,11}$

In the present study, in cases presenting with erectile dysfunction raised BSR was seen in 24 $(24 \%)$ out of 100 cases. There is not much data to look for an incidental raised glucose level in cases presenting with such dysfunction and majority of the studies have shown its prevalence and association with diagnosed cases of DM.

According to a study done by Thorve VS et al, erectile dysfunction in diagnosed cases of both type I and Type II DM was seen in more than 50\% of the cases. ${ }^{12}$ According to a study done by Corona $\mathrm{G}$ et al which was slightly similar to our study, as they included the cases that were recently diagnosed with DM, and it was observed in their study that the erectile dysfunction is more common in cases with DM and also its development is far earlier and began around 10 to 15 years earlier as compared to the normal controls and they further described that these cases were also resistant to oral therapies prescribed for this dysfunction. ${ }^{13}$

In another study done by Anwar $\mathrm{Z}$ et al revealed that out of their 138 cases with DM, 78 (56.52\%) cases had erectile dysfunction and the majority of the cases were seen in age groups less than 50 years, but that was an insignificant difference and so was seen in the present study where this prevalence was almost equal with $p$ value of $0.87 .^{14}$

In this study, raised BSR was significantly high in cases that had duration of ED more than 3 months where it was seen in $21(31.34 \%)$ of cases as compared to $3(9.09 \%)$ of cases with duration less than this with $p$ value of 0.01 . These results were also supported by the number of studies that have shown that longer duration of hyperglycemia and also the cases that had uncontrolled DM, had the increased risk of developing erectile dysfunction. ${ }^{15,16}$ In few other studies they have found that there was linear association with higher levels of $\mathrm{HbAlc}$ with the risk of erectile dysfunction. $^{17,18}$

However, in another large survey of 7689 men they evaluated various risk factor for assessment of this dysfunction especially in cases with diabetes and/or hypertension and it was seen that erectile dysfunction according to the IIEF-5 score was present in $67 \%$ of those with hypertension alone, in $71 \%$ with diabetes alone, and in $77 \%$ of men with both diseases, which was almost three times to the present study, but obviously this was seen in cases with established DM. ${ }^{1 .}$

In a large study comparing healthy controls, the cases with hypertension and those with DM, for assessment of erectile dysfunction they analyzed 145 studies and on extensive analysis, it was observed that the overall prevalence of erectile dysfunction in diabetes was $52.5 \%$ (95\% CI, 48.8 to 56.2$)$ after adjusting for publication bias, and $37.5 \%, 66.3 \%$ and $57.7 \%$ in Type 1, Type 2 and both types of diabetes, respectively ( $\mathrm{P}$ for interaction $<0.0001$ ).

The prevalence of erectile dysfunction was highest in studies using the Sexual Health Inventory for Men $(82.2 \%, 17$ studies, $\mathrm{P}$ for interaction $<0.0001)$. Studies with a higher percentage of people with hypertension moderated our results (beta $=0.03$; 95\% CI, 0.008 to $0.040 ; \mathrm{P}=0.003$; R2 $=0.00$ ). Compared to healthy controls $(\mathrm{n}=5385)$ men with diabetes $(n=863)$ were at increased odds of having erectile dysfunction (OR 3.62; 95\% CI, 2.53 to 5.16; $\mathrm{P}<0.0001 ; \mathrm{I} 2=67 \%, \mathrm{k}=8$ ). Erectile dysfunction is common in diabetes, affecting more than half of men with the condition and with a prevalence odd of approximately 3.5 times more than controls. So they also recommended further in their study that there should be regular screening for the cases with erectile dysfunction for glycemic levels to detect early diabetic changes and might be the presentation of both type I and type II DM. ${ }^{20}$

\section{Conclusion}

Raised random blood sugar is quite common in cases with Erectile Dysfunction and seen in every one out of four cases and is significantly high in cases with duration of Erectile Dysfunction more than 3 months. It is suggested that in cases of Erectile Dysfunction, the treating Physician should consider high blood sugar level as a possible cause and should advise blood sugar testing.

Authors Contribution: FQ: Conception, Design of work and revising. IH: Interpretation and revising. SK: Acquisition and analysis and revising. All the authors gave the final approval for publishing and agreed to be accountable for all aspect of work. 


\section{Conflict of Interest: None \\ Sources of Funding: Self}

\section{References}

1. Hyde Z, Flicker L, Hankey GJ, Almeida OP, McCaul KA, Chubb SA, et al. Prevalence of sexual activity and associated factors in men aged 75 to 95 years: a cohort study. Ann Intern Med 2010; 153(11): 693-7

2. Braun M, Wassmer G, Klotz T, Reifenrath B, Mathers M, Engelmann U. Epidemiology of erectile dysfunction: results of the 'Cologne Male Survey'. Int J Impot Res 2000; 12(6): 305-11.

3. Beckman N, Waern M, Ostling S, Sundh V, Skoog I. Determinants of Sexual Activity in Four Birth Cohorts of Swedish 70-year-olds Examined 1971-2001. J Sex Med 2014; 11: 401-10.

4. Wild S, Roglic G, Green A, Sicree R, King H. Global prevalence of diabetes: estimates for the year 2000 and projections for 2030. Diabetes Care 2004; 27(5): $1047-1053$.

5. Go AS, Mozaffarian D, Roger VL, et al. American Heart Association Statistics Committee and Stroke Statistics Subcommittee Heart disease and stroke statistics - 2013 update: a report from the American Heart Association. Circulation 2013; 127(1): e6-e245.

6. International Diabetes Federation. Diabetes Atlas. 5th ed. Brussels, Belgium: International Diabetes Federation; 2011.

7. Campos C. Chronic hyperglycemia and glucose toxicity: pathology and clinical sequelae. Postgrad Med 2012; 124(6): 90-97.

8. Mykletun A, Dahl AA, O'Leary MP, Fossa SD. Assessment of male sexual function by the Brief Sexual Function Inventory. BJU Int 2006; 97(2): 316-23.

9. Guo W, Liao C, Zou Y, Li F, Li T, Zhou Q, et al. Erectile dysfunction and risk of clinical cardiovascular events: a meta-analysis of seven cohort studies. J Sex Med 2010; 7(8): 2805-16.

10. Stratton IM, Adler AI, Neil HA, et al. Association of glycaemia with macrovascular and microvascular complications of type 2 diabetes (UKPDS 35): prospective observational study. BMJ 2000; 321(7258): 405-412.
11. Lewis RW, Fugl-Meyer KS, Corona G, et al. Definitions/epidemiology/risk factors for sexual dysfunction. J Sex Med 2010; 7(4 Pt 2): 1598-1607.

12. Thorve VS, Kshirsagar AD, Vyawahare NS, Joshi VS, Ingale $\mathrm{KG}$, Mohite RJ. Diabetes-induced erectile dysfunction: epidemiology, pathophysiology and management. J Diabetes Complications 2011; 25(2): 129-136.

13. Corona G, Giorda CB, Cucinotta D, Guida P, Nada E, Gruppo di studio Subito-De. The SUBITO-DE study: sexual dysfunction in newly diagnosed type 2 diabetes male patients. J Endocrinol Invest 2013; 36(10): 864-868.

14. Anwar Z, Sinha V, Mitra S, Mishra AK. Erectile dysfunction: an underestimated presentation in patients with Diabetes Mellitus. Ind J Psychol Med 2017; 39(5): 600-04.

15. Enzlin P, Rosen R, Wiegel M, et al. DCCT/EDIC Research Group Sexual dysfunction in women with type 1 diabetes: long-term findings from the DCCT/EDIC study cohort. Diabetes Care 2009; 32(5): 780-785.

16. Fedele D, Coscelli C, Santeusanio F, et al. Erectile dysfunction in diabetic subjects in Italy. GruppoItaliano Studio Deficit Erettilenei Diabetici. Diabetes Care 1998; 21(11): 1973-1977.

17. Penson DF, Latini DM, Lubeck DP, Wallace KL, Henning JM, Lue TF. Comprehensive Evaluation of Erectile Dysfunction (ExCEED) database Do impotent men with diabetes have more severe erectile dysfunction and worse quality of life than the general population of impotent patients? Results from the Exploratory Comprehensive Evaluation of Erectile Dysfunction (ExCEED) database. Diabetes Care 2003;26(4): 1093-1099.

18. Giugliano F, Maiorino M, Bellastella G, Gicchino M, Giugliano D, Esposito K. Determinants of erectile dysfunction in type 2 diabetes. Int J Impot Res 2010; 22(3): 204-209.

19. Giuliano FA, Leriche A, Jaudinot EO, De Gendre AS. Prevalence of erectile dysfunction among 7689 patients with diabetes or hypertension, or both. Urology 2004; 64: 1196-1201.

20. Kouidrat Y, Pizzol D, Theodore C, Thympson T. High prevalence of erectile dysfunction in diabetes: a systemic review and meta-analysis of 145 studies. Diabet Med 2017;34(9): 1-8.

Article Citation: Qureshi F, Hussain I, Kanjoo SR. Incidental Finding of Raised BSR in Cases Presenting with Erectile JSZMC, 2019;10(4):27-23 